Tetrahedron Letters Digest Article

\title{
Palladium-Catalyzed Construction of Quaternary Carbon Centers with Propargylic Electrophiles
}

\author{
Vilius Franckevičius*
}

Department of Chemistry, Lancaster University, Lancaster LA1 4YB, U.K.

E-mail: v.franckevicius@lancaster.ac.uk

\section{TOC Graphic}

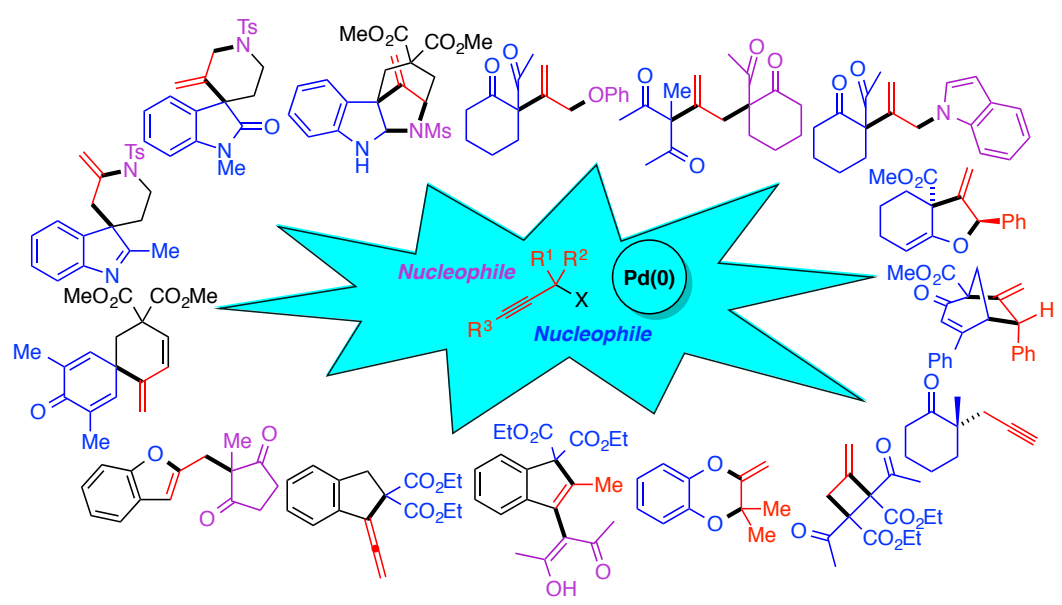

\begin{abstract}
This short review describes the broad reactivity of propargylic electrophiles with nucleophiles under palladium catalysis for the construction of quaternary carbon centers, leading to allenylation, propargylation and alkenylation / allylic alkylation. Although the allenylation and propargylation of a nucleophile can readily create congested carbon centers, these processes often compete and require careful tuning of substrate structure and reactivity of the nucleophile. The alkenylation / allylic alkylation sequence is a much more studied reactivity mode, which results in the coupling of two nucleophiles. This approach is very popular for the rapid generation of molecular complexity, but also poses several chemo- and regioselectivity issues. These selectivity problems have been traditionally overcome by tethering strategies and cyclization reactions. However, over the past few years, highly selective intermolecular coupling reactions of nucleophiles have also been developed. It is, therefore, unsurprising that, as our prowess to control selectivity has grown, the first methods for the palladium-catalyzed enantioselective installation of quaternary carbon centers with propargylic electrophiles have also appeared.
\end{abstract}




\section{Introduction}

The catalytic enantioselective construction of quaternary carbon centers, i.e. ones without hydrogen substituents, is a dynamic area of research owing to their prevalence in natural products and medicinal compounds. ${ }^{1}$ In particular, there is growing interest in $\mathrm{sp}^{3}$-rich compounds as pharmaceuticals owing to their improved bioavailability, enhanced structural diversity and representing untapped areas of chemical space. ${ }^{2}$ However, the direct catalytic construction of quaternary centers has been a long-standing challenge to synthetic chemists because of the need to overcome high steric repulsion between the carbon substituents and the incoming reagent. The development of catalytic methodologies for the direct access to quaternary carbon centers is, therefore, vital towards accessing novel and structurally-rich molecular building blocks for drug discovery programs.

The palladium-catalyzed Tsuji-Trost allylic alkylation reaction has grown over many years to become one of the key methods for the enantioselective construction of quaternary carbon centers (Scheme 1). ${ }^{3}$ In a general process, an allylic electrophile $\mathbf{1}$ undergoes oxidative addition with a palladium( 0 ) catalyst to afford a chiral $\eta^{3}-\pi$-allylpalladium(II) intermediate 2 . A nucleophilic anion, such as an enolate, generated by deprotonation of substrate $\mathbf{3}$ then adds to one of the terminal positions of $\mathbf{2}$ to afford alkylated product $\mathbf{4}$ with concomitant enantioselective installation of a quaternary carbon center, a process directed by a chiral ligand on the palladium center.

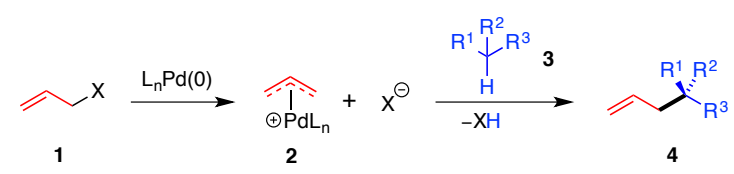

Scheme 1. The Tsuji-Trost allylic alkylation reaction: general process.

In contrast, the reactivity profile of the analogous propargylic electrophiles $\mathbf{5}$ is more complex and much less explored, even within non-enantioselective processes (Scheme 2). Mechanistically, oxidative addition of palladium( 0 ) to $\mathbf{5}$ gives $\eta^{1}$ - $\sigma$-propargylpalladium(II) intermediate $\mathbf{6}$, which may be in equilibrium with $\eta^{1}$ - $\sigma$-allenylpalladium(II) species 7 and $\eta^{3}-\pi$-propargylpalladium(II) cation $\mathbf{8}{ }^{4} \eta^{3}-\pi$-Propargylpalladium(II) intermediate $\mathbf{8}$ has been previously characterized. ${ }^{5}$ At this point, intermediate $\mathbf{8}$ can display three distinct modes of reactivity. Addition of the nucleophile to $\mathrm{C} 1$ in $\mathbf{8}$ can lead to allenylated product $\mathbf{9}$, whereas addition to $\mathrm{C} 3$ results in propargylation (10). ${ }^{6}$ Although there are exceptions, generally, hard nucleophiles prefer to react via one of these pathways. However, it is typical that, with soft nucleophiles, two equivalents of the nucleophile undergo reaction with 8 . ${ }^{7}$ Specifically, addition at the central position $\mathrm{C} 2$ of $\mathbf{8}$ takes place to give rise to putative palladacyclobutene intermediate $\mathbf{1 1}$, which can alternatively be viewed as palladium carbene 12. At this point, intermediate $\mathbf{1 1}$ is protonated by a second equivalent of the nucleophile to give rise to $\eta^{3}$ - $\pi$-allylpalladium(II) intermediate 13. Although matallacyclobutenes of rhenium, ${ }^{8}$ as well as iridium and platinum, ${ }^{9}$ have been isolated, it must be emphasized that, to date, no experimental evidence has been put forward to corroborate the existence of palladacyclobutene intermediates. Therefore, it is entirely plausible that nucleophilic addition at the central carbon atom of $\mathbf{8}$ is followed by immediate protonation to give $\eta^{3}$ - $\pi$-allylpalladium(II) intermediate $\mathbf{1 3}$ in a fully synchronous manner. ${ }^{5 b}$ In the final step, allylic alkylation of the anion of the nucleophile at one of the terminal positions affords product 14. Overall, in the transformation of 5 to 14 , one equivalent of the nucleophile has undergone an alkenylation process and another, an allylic alkylation reaction. The regioselectivity of nucleophilic addition to intermediate 8 (at $\mathrm{C} 1, \mathrm{C} 2$ or $\mathrm{C} 3$ ) is highly dependent on a number of factors (vide infra), including the inter- and intramolecular nature of the reaction, the ligand for palladium employed and the type of nucleophile used. Some of these factors have been the subject of theoretical studies in order to rationalize the observed regioselectivity. ${ }^{10}$ 


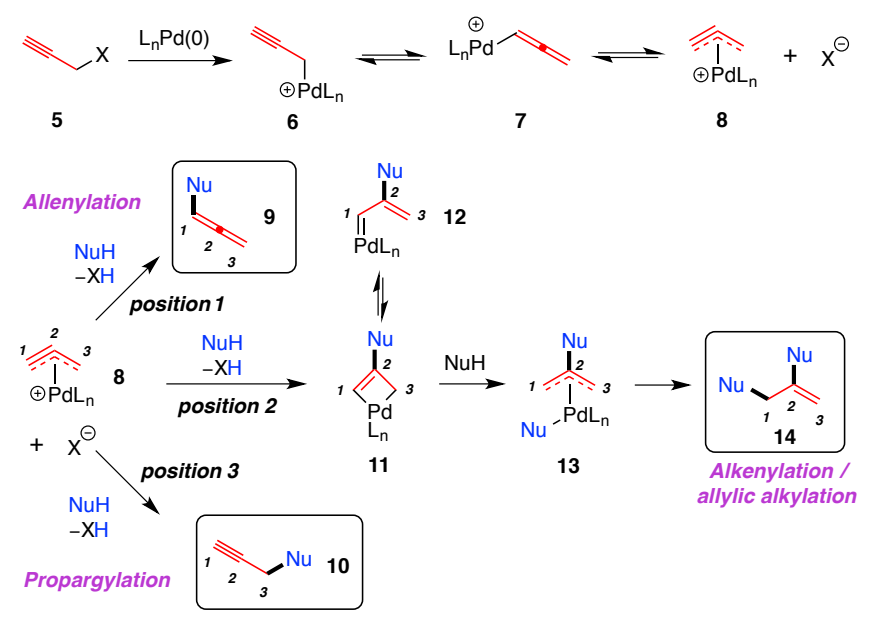

Scheme 2. Palladium-catalyzed reactions of propargylic electrophiles.

This review gives an overview of the palladium-catalyzed reactions of propargylic electrophiles that enable the installation of a quaternary carbon center at the following positions via each of the three main pathways (Figure 1): a) via allenylation of the nucleophile (15); b) via propargylation of the nucleophile (16; or 17 by using tertiary electrophiles); c) via alkenylation / allylic alkylation of one or both of the nucleophiles in 18; or 19 by using tertiary electrophiles. The strategies to control the possible reactivity pathways and very recent developments in the palladium-catalyzed enantioselective construction of quaternary centers with propargylic electrophiles are discussed.

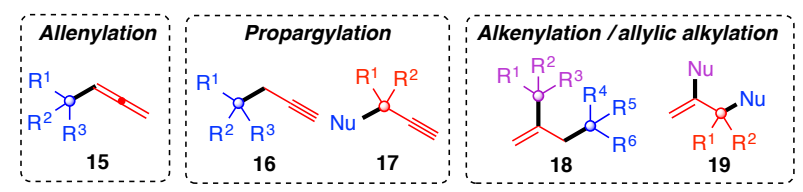

Figure 1. Positions of quaternary carbon center installation.

\section{Reactivity of Propargylic Electrophiles with Hard Nucleophiles}

The ability to install a quaternary carbon center by propargylation of hard nucleophiles with substituted propargylic electrophiles $\mathbf{2 0}$ is challenging as the allenylation pathway tends to outcompete propargylation for steric reasons (Scheme 3). ${ }^{11}$ Specifically, $\eta^{1}$-б-allenylpalladium(II) intermediate 22, formed by oxidative addition of palladium $(0)$ to $\mathbf{2 0}$, is less sterically hindered than $\eta^{1}$-б-propargylpalladium(II) intermediate 21, both of which are part of an equilibrium. As such, reductive elimination of $\mathbf{2 2}$ to give allene products of type $\mathbf{2 6}$ tends to dominate.

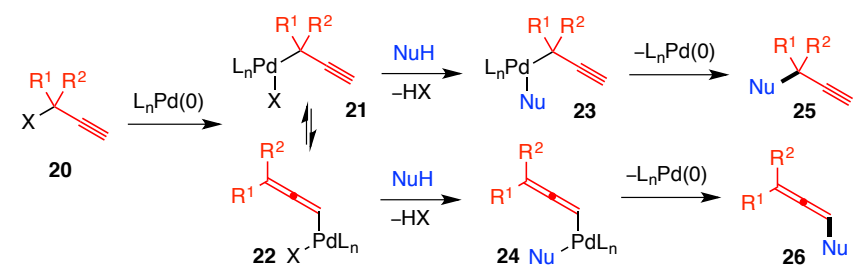

Scheme 3. Propargylation versus allenylation of hard nucleophiles.

Morken et al. overcame this challenge by utilizing allyl boronic ester $\mathbf{2 8}$ as the nucleophile in the cross-coupling with propargylic acetate $\mathbf{2 7}$ for the synthesis of 1,5-enynes $\mathbf{2 9}$ (Scheme 4). ${ }^{12}$ The success of this approach was based on the migration of the allyl group in the reductive elimination step from 31, giving rise to propargylated 29 as the major product. Although the authors focused on secondary propargylic acetates, it was shown that a quaternary all-carbon center can be introduced 
not only with high regioselectivity (29a), but also with complete conservation of enantiomeric enrichment (29b) when a chiral propargylic acetate was used.

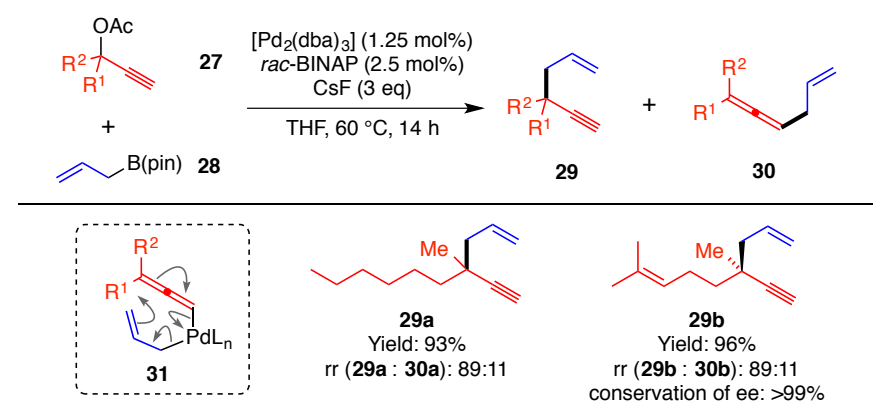

Scheme 4. Allyl-propargyl cross-coupling.

Concerning the reactivity of enolates, the first report of the reaction of an aldehyde enolate with a propargylic electrophile in the presence of a palladium catalyst was disclosed by Bienaymé (Scheme 5). ${ }^{13}$ The reaction was performed in a decarboxylative manner by utilizing conjugated enol carbonates 32, resulting in the allenylation and propargylation of the enolate and giving rise to products 33 and 34, respectively. With a fully unsubstituted propargyl carbonate as the substrate, 34 was formed as a single regioisomer. However, when substitution $\left(\mathrm{R}^{1}\right.$ and $\left.\mathrm{R}^{2}\right)$ in carbonates 32 was introduced in order to install a quaternary carbon center in propargylated product $\mathbf{3 4}$, it was formed as a minor product in most cases, presumably owing to steric factors. This selectivity trend could not be reversed even by introducing a large substituent $\mathrm{R}^{3}$ at the acetylenic position, such as TMS or phenyl. Making use of allenylated products of type 33, the authors disclosed a synthesis of polyconjugated retinal. ${ }^{14}$

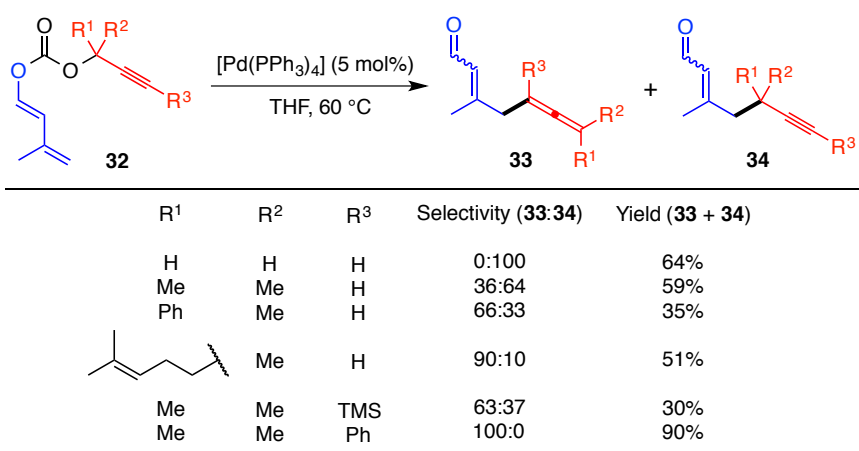

Scheme 5. Decarboxylative allenylation and propargylation of aldehyde enolates.

In spite of the difficulties associated with the selective propargylation of enolates, ${ }^{15}$ the Stoltz group recently reported the first example of an enantioselective decarboxylative propargylic alkylation of a ketone enolate (Scheme 6). ${ }^{16}$ Using 9-anthracenyl PHOX ligand 37, propargylated ketone 36 was formed as a single regioisomer in high yield and moderate enantioselectivity with the concomitant construction of an $\alpha$-quaternary all-carbon center.

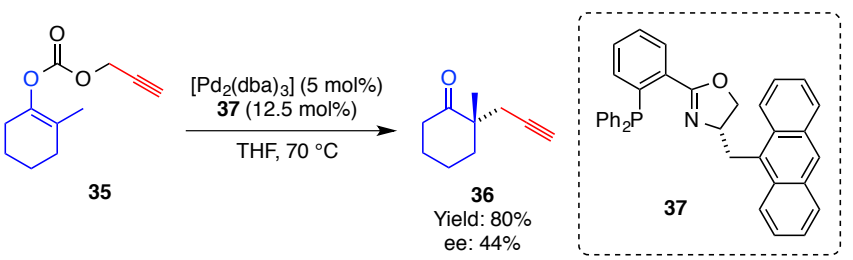

Scheme 6. Decarboxylative propargylic alkylation of a ketone enolate. 
In spite of the observations that aldehyde and ketone enolates prefer to undergo either allenylation or propargylation via addition to one of the terminal positions of the $\eta^{3}-\pi$-propargylpalladium(II) intermediate, Yoshida et al. discovered that the analogous decarboxylative process with monosubstituted $\beta$-ketoesters $\mathbf{3 8}$ resulted in the reaction of the transient ketone enolate at the central carbon atom of the $\eta^{3}$ - $\pi$-propargylpalladium(II) intermediate 39 to afford a range of tetrasubstituted furans 40a-d (Scheme 7). ${ }^{17}$ This work demonstrates that the regioselectivity of enolate addition to $\eta^{3}$ - $\pi$-propargylpalladium(II) intermediates may not always be easily predicted and can be heavily influenced by substrate structure, substitution pattern or ligands employed.

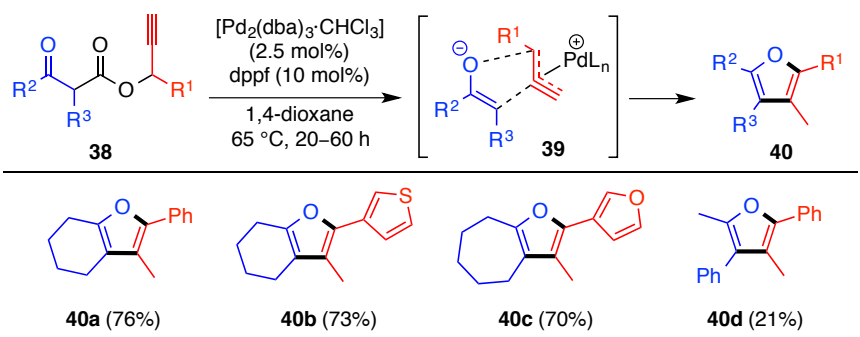

Scheme 7. Furan synthesis via decarboxylative alkenylation of ketone enolates.

\section{Reactivity of Propargylic Electrophiles with Soft Nucleophiles}

As alluded to previously (vide supra, Scheme 2), hard nucleophiles typically react with $\eta^{3}$ $\pi$-propargylpalladium(II) intermediates at one of the terminal carbon atoms, leading to either propargylation or allenylation, whereas soft nucleophiles, such as stabilized enolates of 1,3dicarbonyl compounds, undergo an alkenylation / allylic alkylation by sequential nucleophilic addition to the central and terminal carbon atoms of the $\eta^{3}-\pi$-propargylpalladium(II) intermediate. Concerning the latter, the most straightforward cases are those when two equivalents of the same nucleophile are used. In the seminal report of the reactivity of propargyl carbonates with soft carbon-based nucleophiles under palladium catalysis, Tsuji and co-workers described the reaction of propargyl carbonate 41 with two equivalents of $\beta$-ketoester $\mathbf{4 2}$, which enabled the installation of two quaternary centers in $\mathbf{4 3}$ in a single step (Scheme 8). ${ }^{18}$

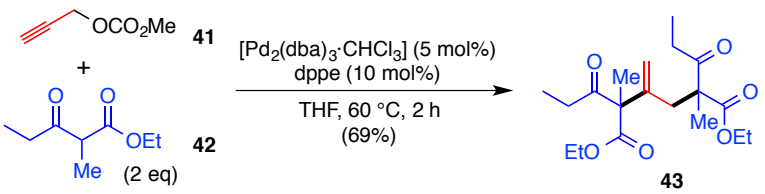

Scheme 8. Alkenylation / allylic alkylation sequence with soft nucleophiles.

Subsequently, Lu et al. demonstrated how a similar concept could be applied in a cyclization reaction (Scheme 9). ${ }^{19}$ Specifically, propargyl carbonate $\mathbf{4 1}$ underwent double nucleophilic addition with 2,3-diacetylsuccinate (44) in the presence of palladium(0). Remarkably, the highly strained 4membered ring 45, a kinetically controlled product, was formed via $C$-allylic alkylation in THF/acetonitrile as the solvent and $\left[\mathrm{Pd}\left(\mathrm{PPh}_{3}\right)_{4}\right]$ as the catalyst at room temperature. In contrast, the more stable 6-membered ring 46, a thermodynamically controlled product, was generated exclusively via $O$-alkylation by using dppe as the ligand in refluxing acetonitrile. 


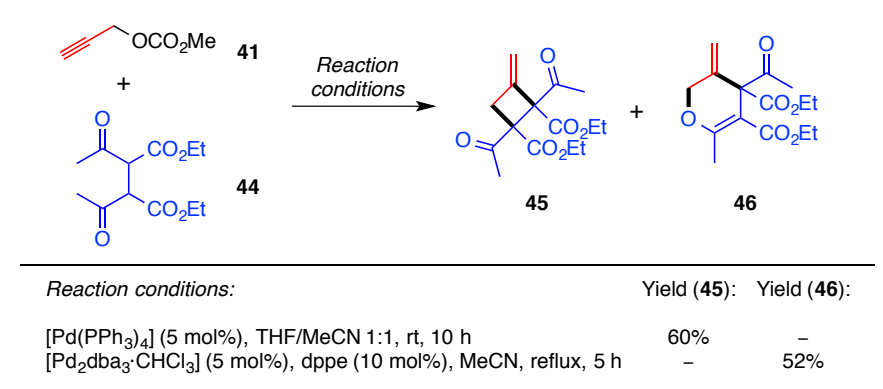

Scheme 9. Cyclization with 2,3-diacetylsuccinate.

In order to avoid the undesired $O$-alkylation, the authors explored the use of diester-based dinucleophiles 47 (Scheme 10). ${ }^{20}$ Whilst, surprisingly, cyclobutane product 48a had not been formed, the reaction did successfully generate cyclic products $\mathbf{4 8 b}-\mathbf{d}$ by extending the carbon chain in 47.

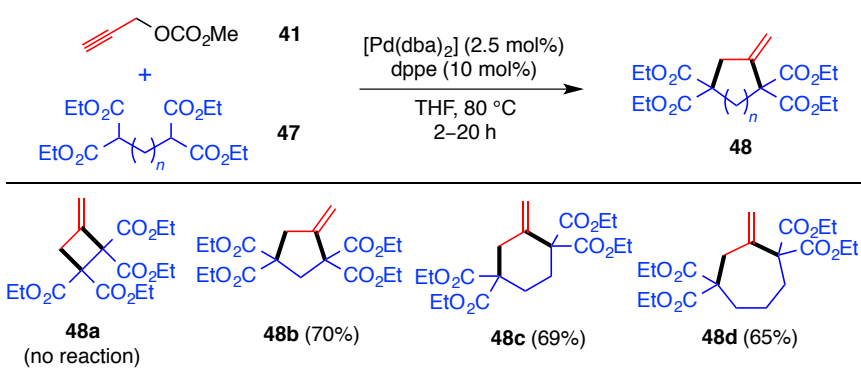

Scheme 10. Cyclization with soft carbon dinucleophiles.

Subsequently, Sinou et al. demonstrated that catechol (50) could also act as a symmetrical, soft oxygen dinucleophile owing to the similarity in acidity of phenols and 1,3-dicarbonyl compounds (Scheme 11). ${ }^{21}$ In the resulting cyclic product 51, the quaternary carbon center was installed at the allylic position owing to the substituted nature of carbonate 49. Whilst the formation of regioisomer 52 was also possible, nucleophilic addition exclusively at the more substituted position was observed for products $\mathbf{5 1 a}-\mathbf{d}$. The authors argued that the $\eta^{3}-\pi$-allylpalladium(II) intermediate was likely to be a cationic species, with substitution taking place at the more substituted carbon atom for electronic reasons owing to the higher positive charge at that center in either the $\pi$-allylpalladium(II) intermediate or the transition state. This observation is at odds with the direct palladium-catalyzed alkylation of nucleophiles with allylic electrophiles, a process that typically results in addition at the less substituted end of the allylic system. ${ }^{3 a}$ In contrast, larger substituents, such as isopropyl (51e and 52e) and benzyl (51f and 52f), led to a mixture of regioisomers. This could be due to competing steric effects, whereby the more substituted, and hence more electrophilic, center is too crowded, resulting in reduced regioselectivity. Indeed, subsequent theoretical studies indicated that the regioselectivity was dependent on the nature of the phosphine used, the steric bulk of the substituents and their electronic properties. ${ }^{10 a}$ 


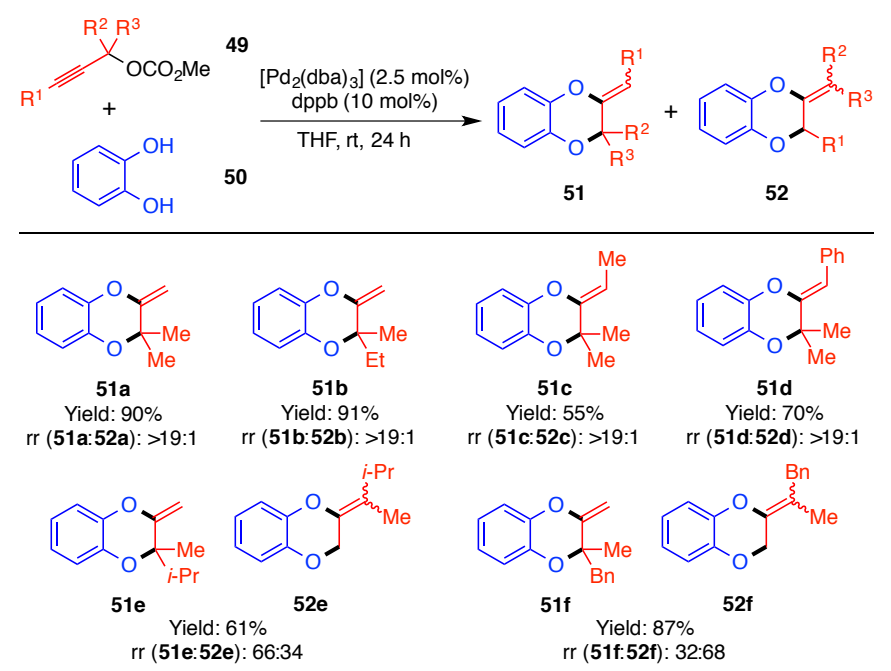

Scheme 11. Cyclization with catechol dinucleophiles.

The same authors were also successful at developing enantioselective variants of this reaction with secondary propargylic carbonates $49\left(\mathrm{R}^{2}=\mathrm{H}\right){ }^{22}$ However, only one example $\left(\mathbf{5 1 b}, \mathrm{R}^{2}=\mathrm{Me}, \mathrm{R}^{3}=\right.$ Et) was investigated with respect to the enantioselective installation of a quaternary center. ${ }^{23}$

Unfortunately, no practical levels of enantioselectivity were induced, presumably owing to the small difference in steric size between methyl and ethyl substituents. Subsequently, the Yoshida group reported the enantioselective construction of structurally similar chromans; however, only secondary propargylic carbonates had been utilized. ${ }^{24}$ This demonstrates that the stereoselective installation of quaternary carbon centers through this approach remains to be a formidable task.

\section{Reactivity of Propargylic Electrophiles with Soft Nucleophiles: Selectivity Issues}

The above palladium-catalyzed reactions of propargylic electrophiles with soft nucleophiles utilized either two equivalents of the same nucleophile or one equivalent of a symmetrical dinucleophile. The utility of this process becomes much broader when two different nucleophiles are used. However, there are a number of challenges associated with such a one-pot process (A, Scheme 12). Firstly, the order of addition of the two nucleophiles must be controlled ( $\mathbf{5 3}$ versus 54). Secondly, allylic alkylation of the same nucleophile, leading to homocoupled products 55 and $\mathbf{5 6}$, or $\mathbf{6 1}$ and $\mathbf{6 2}$, must be prevented. Thirdly, even if the successful cross-coupling reaction takes place with the second nucleophile, the allylic alkylation step could occur at either the more or the less substituted end (57 versus 58 and $\mathbf{5 9}$ versus $\mathbf{6 0}$ ) if the $\eta^{3}-\pi$-allylpalladium(II) intermediate is not symmetrical. Overall, without taking into account the resulting $\mathrm{C}-\mathrm{C}$ double-bond geometry or any stereoisomerism, as many as eight potential products could be formed if a fully substituted propargyl carbonate 49 is used as the electrophile. Two key strategies to control the selectivity issues have been adopted to date $(\mathrm{B}$, Scheme 12$)$, both resulting in a cyclization reaction. The first is to tether one of the nucleophiles to the propargylic electrophile 63. In this way, cyclization with the tethered nucleophile takes place first (64) owing to the intramolecular nature of the reaction, provided that a stable ring can be formed. The externally added nucleophile then undergoes the intermolecular allylic alkylation step at either the more or the less substituted position ( 65 versus 66). An alternative approach is to tether the two latent nucleophiles (67) and promote the initial reaction of only one of the nucleophiles to give intermediate $\mathbf{6 8}$. This could be achieved by selective deprotonation owing to a large difference in acidity of the two nucleophiles, or by exploiting the difference in the relative nucleophilicity or steric size between them. Subsequent intramolecular allylic alkylation of the second tethered nucleophile would then result in cyclization to 69 or 70 . If $\eta^{3}$ - $\pi$-allylpalladium(II) intermediate $\mathbf{6 8}$ is unsymmetrical, then the regioselectivity of this step would also have to be controlled. These two cyclization strategies for the control of regioselectivity are reviewed next. 


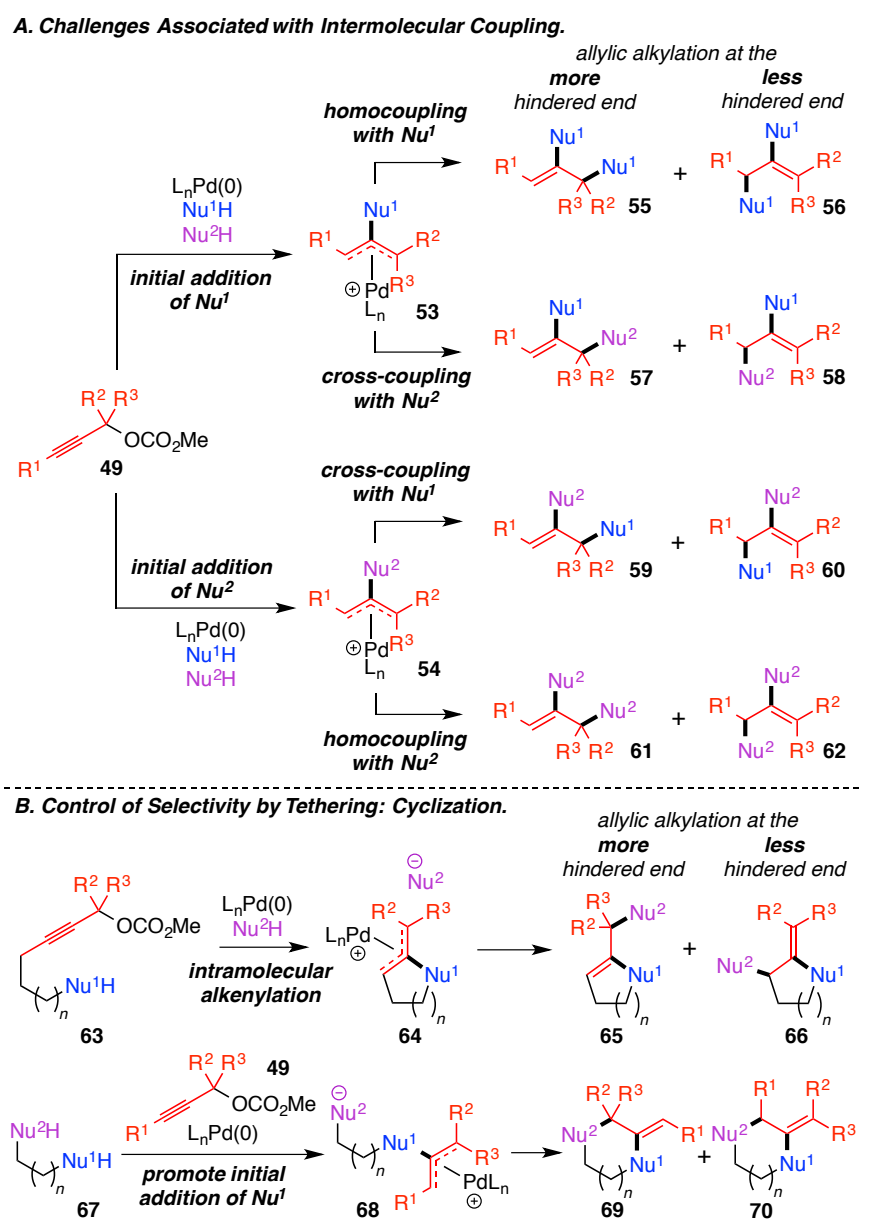

Scheme 12. Control of selectivity in reactions with soft nucleophiles.

\section{Control of Selectivity: Cyclization Reactions of Propargylic Electrophiles with Soft Nucleophiles}

In this context, Liang and co-workers demonstrated that propargylic carbonates 71, appended with a malonate nucleophile, readily reacted in the presence of 1,3-dicarbonyl nucleophiles $\mathbf{7 2}$ to afford 2,3-disubstituted indenes $\mathbf{7 3}$ (Scheme 13). ${ }^{25}$ The tethered diethylmalonate is alkenylated in an intramolecular fashion with complete regioselectivity, thus installing an all-carbon quaternary center in 73. Allylic alkylation of the externally added 1,3-dicarbonyl compound $\mathbf{7 2}$ then follows exclusively at the more substituted carbon atom for electronic reasons with subsequent isomerization of the $\mathrm{C}-\mathrm{C}$ double bond in 73. Linear and cyclic 1,3-diketones (73a and 73b), as well as $\beta$-ketoesters (73c) can also be successfully used. Malonates (73d), however, did not take part in the desired reaction. 


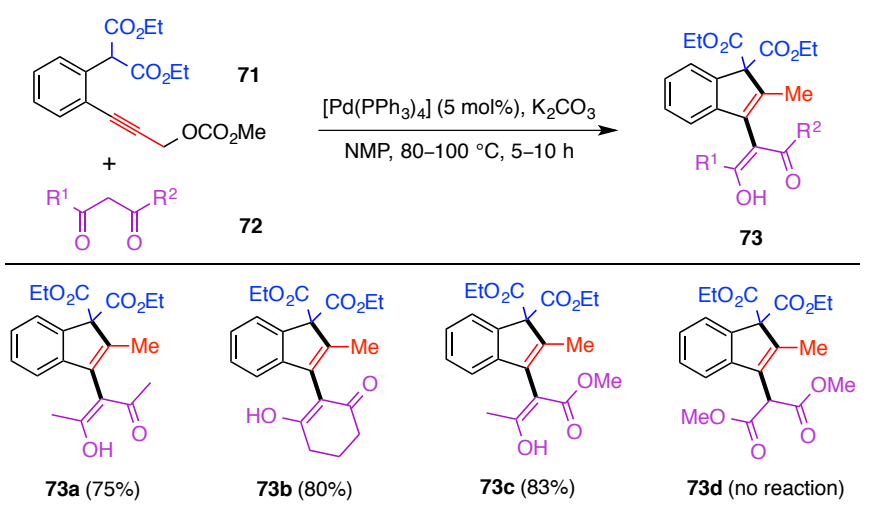

Scheme 13. Cyclization with tethered carbon nucleophiles in the presence of 1,3-dicarbonyls.

The same research group extended this work to other external nucleophiles, including phenols $\mathbf{7 4}$ and amines 75 (Scheme 14). ${ }^{26}$ The first nucleophilic addition step involved the tethered malonate in 71 to install the desired quaternary center in $\mathbf{7 6}$, as expected. However, in contrast to the use of 1,3dicarbonyl nucleophiles, allylic alkylation of the externally added phenol or amine nucleophile occurred at the less substituted position. Simple phenol, as well as substitution with electronwithdrawing, -donating and halogen groups gave high yields of products (76a-d). In the case of amines 75, the use of a base was essential in order to obtain high yields of product containing cyclic amines (76e and 76f), linear amines (76g), as well as amides (76h). Using similar substrates, Liang and co-workers later expanded the utility of this process to the use of terminal alkynes as external nucleophiles, which subsequently underwent a tandem $\mathrm{C}-\mathrm{H}$ activation / cyclization process. ${ }^{27}$

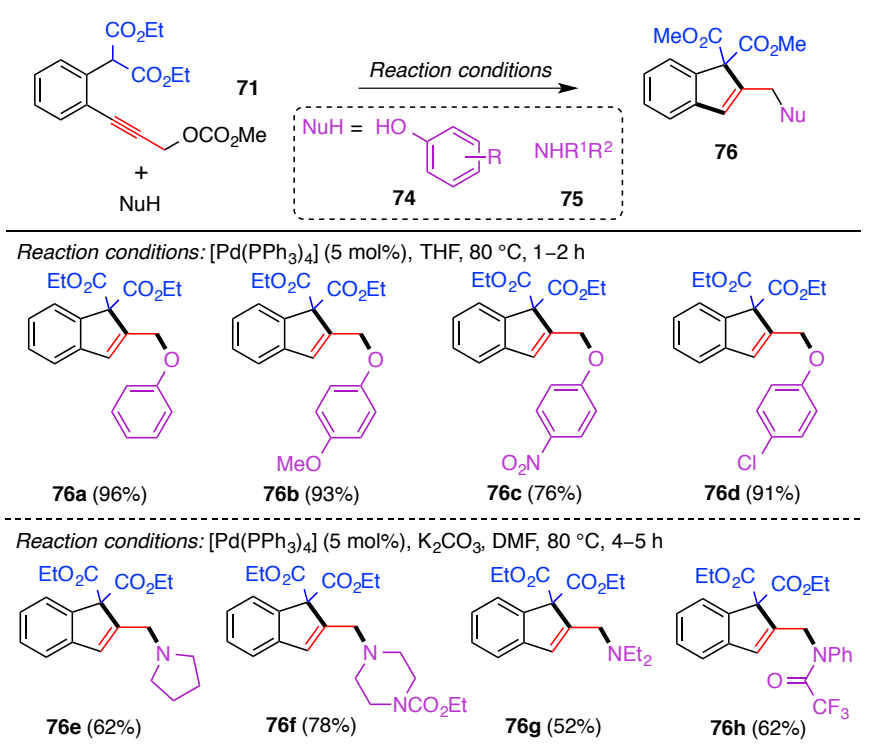

Scheme 14. Cyclization with tethered carbon nucleophiles in the presence of phenols and amines.

A contrasting reactivity profile was observed with substrates $\mathbf{7 7}$, in which the chain bearing the malonate anchor had been extended by one carbon atom (Scheme 15). ${ }^{28}$ The reaction was found to be highly regioselective in favor of the formation of a 5-membered ring in $\mathbf{7 8}$, appended with an exocyclic allene, rather than a 6-membered ring arising from addition to the central carbon atom of a $\pi$-propargylpalladium(II) intermediate. As such, an enolate of the malonate underwent a cyclization to install a quaternary center, and a range of allenes $\mathbf{7 8 a}-\mathbf{d}$ were obtained in the absence of an external nucleophile. The reactions proceeded with just palladium on charcoal as the catalyst without a phosphine ligand at room temperature. More hindered tertiary substrates required the use of $\left[\mathrm{Pd}_{2}(\mathrm{dba})_{3}\right]$ as the catalyst at elevated temperature, and the yields of tetrasubstituted allenes $\mathbf{7 8 e}-$ h were consistently high. 


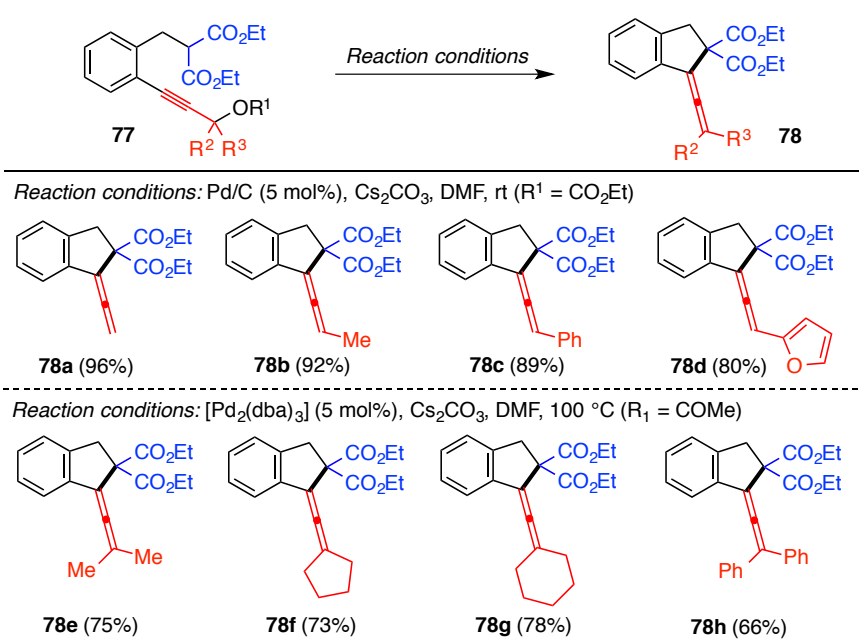

Scheme 15. Cyclization with tethered carbon nucleophiles in the absence of external nucleophiles.

It was later discovered that the desired enolate of the malonate can be generated in situ via a Michael addition of a range of amines 80 to $\alpha, \beta$-unsaturated malonate 79, which can then undergo the desired cyclization to allenes 81a-d (Scheme 16). ${ }^{29}$ Aromatic amines with a range of substituents, as well as aliphatic benzylamine were all shown to participate in the desired reaction.

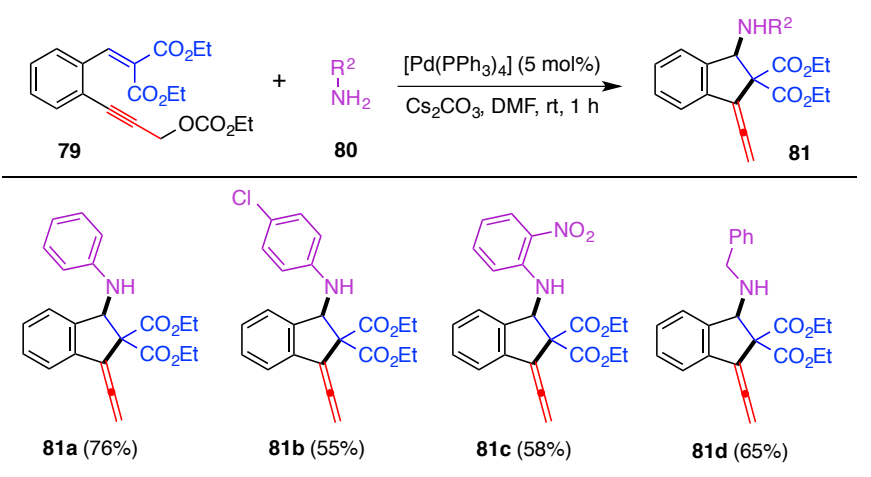

Scheme 16. Tandem Michael addition / cyclization.

A further intriguing observation was made when propargylic carbonate $\mathbf{8 2}$ was reacted in the presence of phenol (83) as the external nucleophile (Scheme 17) ${ }^{30}$ The authors devised a process that could give rise to either allene 78a with $\left[\mathrm{Pd}\left(\mathrm{PPh}_{3}\right)_{4}\right]$, or indene 84a with $\left[\mathrm{Pd}_{2}(\mathrm{dba})_{3}\right]$ and dppf as catalysts. It would be expected that the initial intramolecular addition of the enolate to the central carbon atom of the $\eta^{3}$ - $\pi$-propargylpalladium(II) intermediate would give a 6-membered ring, followed by intermolecular addition of phenol (83). However, formation of $\mathbf{8 4 a}$ was unusual in that the intermolecular addition of phenol $(\mathbf{8 3})$ had taken place faster than the intramolecular cyclization of the enolate of malonate. The ability to generate allene 78a under some reaction conditions, and the observation that intermolecular addition of phenol (83) occurs faster than intramolecular attack of the enolate, suggests that formation of a 5-membered ring is much more favored than that of a 6membered ring in this system. Thus, using dppf as the ligand, the authors demonstrated broad substrate scope of the reaction $(\mathbf{8 4} \mathbf{b}-\mathbf{e})$ with a range of phenol nucleophiles. 

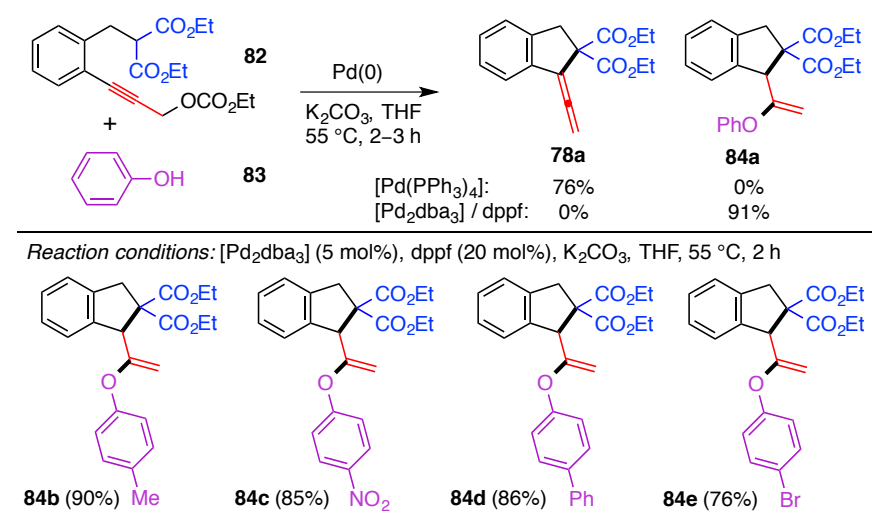

Scheme 17. Carboannulation with phenol nucleophiles.

Access to exocyclic allenes in these processes prompted the Liang group to exploit the reactivity of these products in a tandem double-cyclization sequence for the synthesis of spirocyclic compounds $\mathbf{8 6}$ (Scheme 18). The reaction commences with the palladium-catalyzed cyclization of $\mathbf{8 2}$ to allene 78a, in which a quaternary carbon center had been installed via the usual reaction pathway. At this point, in the presence of 2-iodophenol 85, a regioselective carbopalladation of 87 to allene $\mathbf{7 8 a}$ takes place to give $\eta^{3}$ - $\pi$-allylpalladium(II) intermediate $\mathbf{8 8}$. Product $\mathbf{8 6}$ is then obtained by an intramolecular spirocyclization regioselectively at the more hindered position, presumably owing to the benzylic stabilization of partial positive charge in 88. A selection of 2-iodophenols, appended mostly with electron-withdrawing substituents, as well as a methyl substituent, gave rise to the desired spirocycles 86a-d. Subsequently, the use of analogous propargylic electrophiles led to the synthesis of tetracyclic benz $[a]$ anthracene frameworks via a palladium-catalyzed $\mathrm{C}-\mathrm{H}$ activation / double-cyclization cascade. ${ }^{31}$

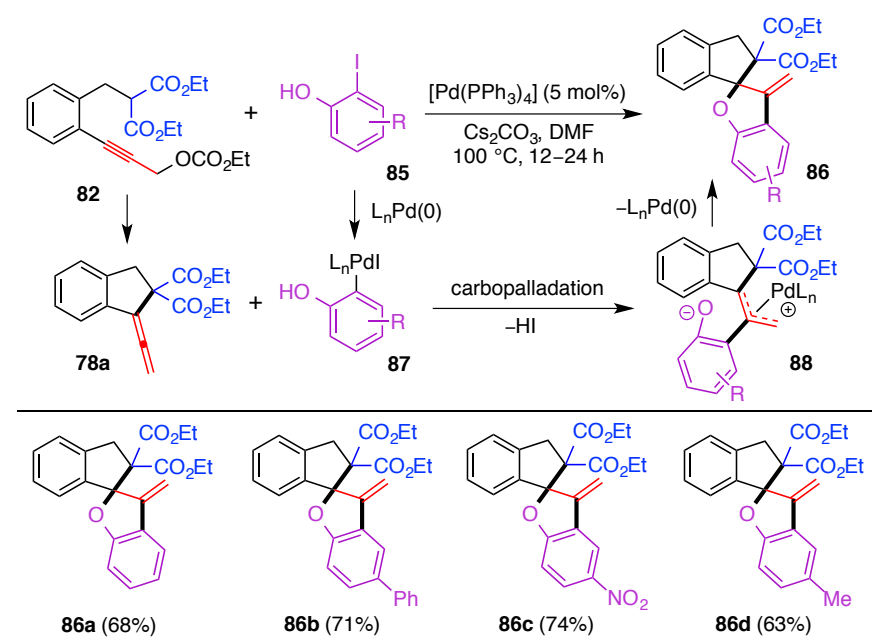

Scheme 18. Regioselective spirocyclization reaction.

By tethering the propargylic electrophile to a phenol, Yoshida and co-workers developed a palladium-catalyzed cyclization reaction of $\mathbf{8 9}$ in the presence of an external cyclic 1,3-diketone $\mathbf{9 0}$ for the synthesis of benzofurans 91a and 91b (Scheme 19). ${ }^{32}$ In this process, intramolecular cyclization takes place first, followed by the regioselective addition of 1,3-dicarbonyl 90 at the less hindered site of the $\pi$-allylpalladium(II) intermediate, thus installing an $\alpha$-quaternary center in $\mathbf{9 1 a}$ and 91b. 


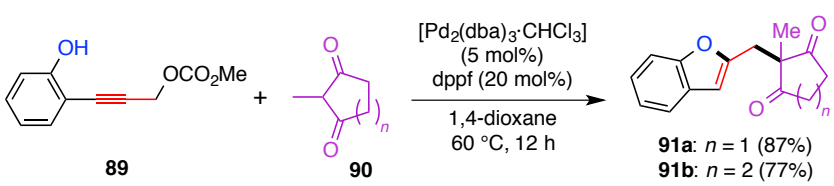

Scheme 19. Benzofuran synthesis with 1,3-dicarbonyl nucleophiles.

In 2013, Hamada et al. reported the first example of a palladium-catalyzed dearomatization of phenol 92, tethered to a propargylic carbonate, to give rise to spirocycle 93a (Scheme 20). ${ }^{33}$

Mechanistic studies have shown that, in the first instance, oxidative addition of palladium(0) to 92 generates palladacycle 94, which undergoes reductive elimination to allene 95. At that point, rearomatization-assisted oxidative addition of palladium(0) to 95 affords $\eta^{3}$ -

$\pi$-propargylpalladium(II) intermediate 96. Dearomative cyclization of the phenol at the central carbon atom of $\eta^{3}-\pi$-propargylpalladium(II) motif in 96 installs a quaternary all-carbon center and, in the absence of an external nucleophile, diene 93a is formed. An investigation of the substrate scope of the reaction indicated broad tolerance of phenol substitution and the types of tether used $(\mathbf{9 3 b}-\mathbf{e})$.

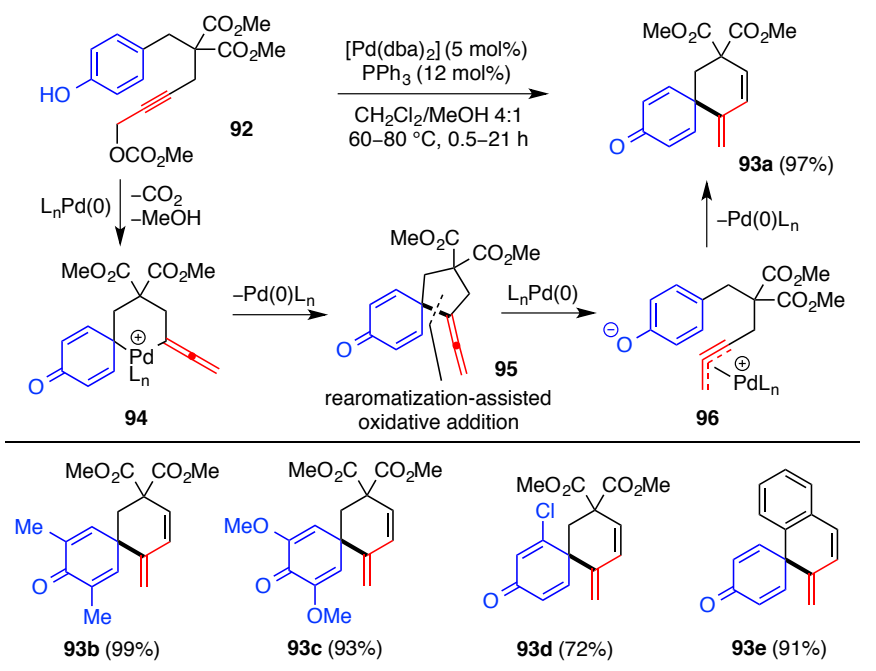

Scheme 20. Dearomatization of phenols.

The authors discovered that the same reaction conditions could be readily applied to the dearomatization reaction of indoles 97 , installing a quaternary all-carbon center in spirocyclic indolenines 98 (Scheme 21). ${ }^{33}$ Overall, several tryptamine derivatives 97 were tested and the desired transformation resulted in spirocycles $\mathbf{9 8 a}-\mathbf{c}$ in good yields.

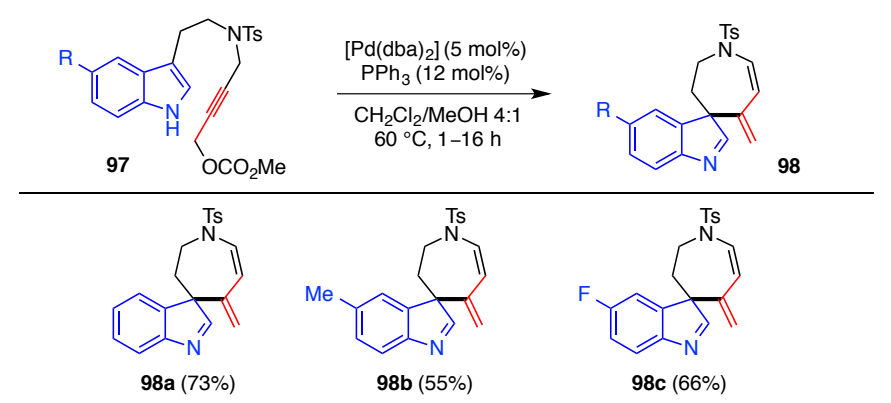

Scheme 21. Dearomatization of indoles.

Ohno et al. extended this method by utilizing an external nucleophile $\mathbf{1 0 0}$ for the dearomatization of indoles 99 (Scheme 22). ${ }^{34}$ Using dppb as the bidentate phosphine, tetracyclic products 101 were 
obtained, along with a small amount of 102, which arose from $\beta$-hydride elimination with the external nucleophile not being incorporated. Mesyl and tosyl amines as nucleophiles afforded the desired polycyclic products $\mathbf{1 0 1 a}-\mathbf{d}$ in good yields, wherein the nucleophile had added to the more substituted position of the intermediate $\eta^{3}-\pi$-allylpalladium(II) system. In contrast, with acetylacetone and dimethyl malonate as nucleophiles, products 103 and 104, respectively, were obtained owing to addition of the nucleophile to the less substituted position of the $\eta^{3}$ $\pi$-allylpalladium(II) intermediate, whereas formation of 101e was not observed.

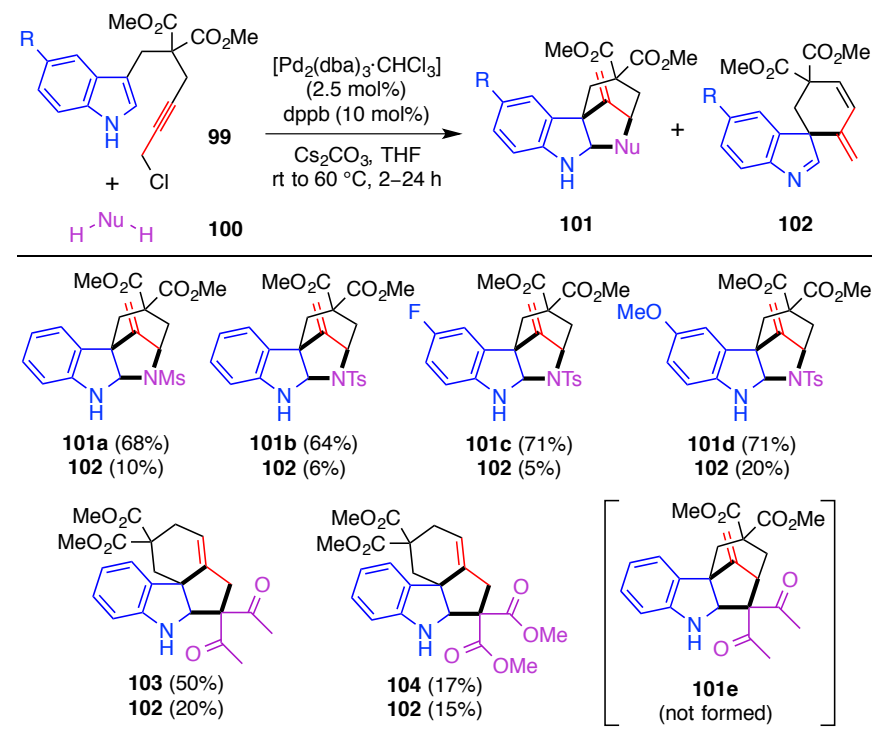

Scheme 22. Dearomatization of indoles in the presence of external nucleophiles.

The reactions discussed so far utilized substrates in which one of the nucleophiles is strategically tethered to the propargylic electrophile so that the order of addition of nucleophiles can be controlled by relying on the much faster rate of intramolecular cyclization. The second strategy to control the regioselectivity is to tether the two nucleophiles, making sure that either one of the latent nucleophiles can be selectively deprotonated in the presence of the other, or, if the acidity of the nucleophiles is similar, one nucleophile is significantly more nucleophilic than the other (vide supra, $\mathrm{B}$, Scheme 12). The first example of this approach for the installation of quaternary carbon centers was disclosed by Yoshida et al. (Scheme 23). ${ }^{35}$ In this work, propargylic carbonates 105 were reacted with substituted dimedone $\mathbf{1 0 6}$ under palladium catalysis to afford bicyclic systems of type 107 with complete diastereoselectivity and simultaneous construction of an $\alpha$-stereogenic quaternary all-carbon center. The carbon atom adjacent to the two carbonyl groups in $\mathbf{1 0 6}$ is the most acidic and, therefore, enolate $\mathbf{1 0 9}$ is the first to add to the central carbon atom of $\eta^{3}$ $\pi$-propargylpalladium(II) intermediate 108 to give palladacyclobutene $\mathbf{1 1 0}$. Then, the much less facile enolization of the ketone in $\mathbf{1 1 0}$ and enolate $O$-alkylation at the more substituted position of the allylic system in $\mathbf{1 1 1}$ gives rise to $\mathbf{1 0 7}$ with complete diastereoselectivity. Substitution of both propargylic carbonate 105 and dimedone 106 was tolerated to give products $107 \mathbf{a}-\mathbf{d}$ in good yields with diphosphine ligands for palladium. 


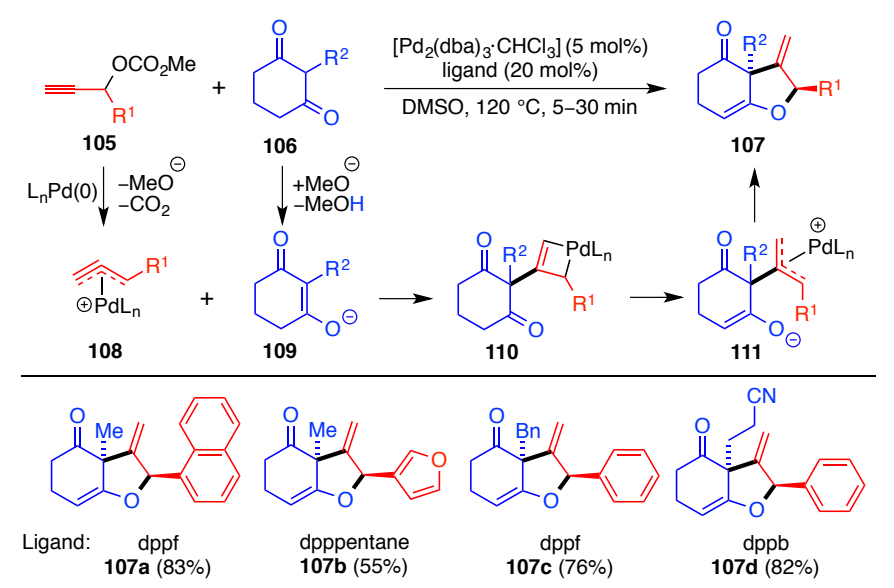

Scheme 23. Diastereoselective tetrahydrobenzofuranone synthesis.

The successful control of the order of addition in this reaction led to the extension of this process to $\beta$-ketoesters 112 as dinucleophiles for the synthesis of bicyclic systems $\mathbf{1 1 3}$ with complete stereoselectivity (Scheme 24). ${ }^{36}$ Products 113a-d, decorated with both aryl and alkyl substituents, were accessible through this approach.

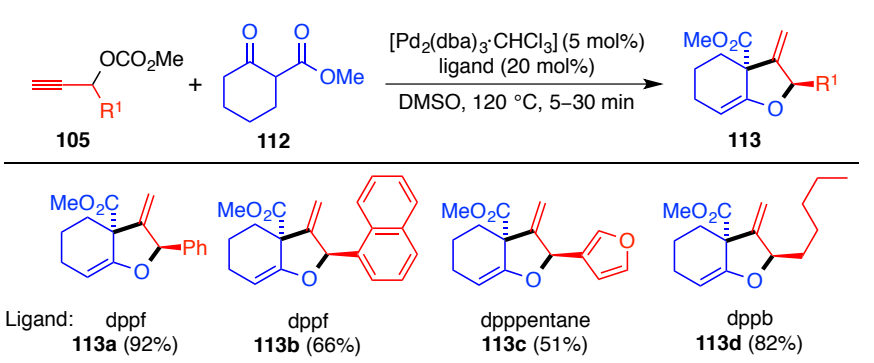

Scheme 24. Diastereoselective cyclization of $\beta$-ketoesters.

Subsequently, the Yoshida group disclosed the use of $\beta$-cyclohexenone esters 114 in a similar cyclization, wherein an extended ketone enolate was to act as one of the nucleophiles (Scheme 25) ${ }^{37}$ However, in contrast to simple $\beta$-ketoesters 112, which underwent $O$-alkylation, in this case, $C$-alkylation of the $\gamma$-position of the extended enolate at the more hindered end of the $\eta^{3}$ $\pi$-allylpalladium(II) intermediate took place (116) to afford bicyclic structures 117. A range of novel bicyclic products $\mathbf{1 1 7} \mathbf{a}-\mathbf{e}$ were obtained by exploring the substitution of propargylic acetates $\mathbf{1 1 5}$ with aryl and alkyl groups, as well as ether and aryl moieties at enone $\mathbf{1 1 4}$.

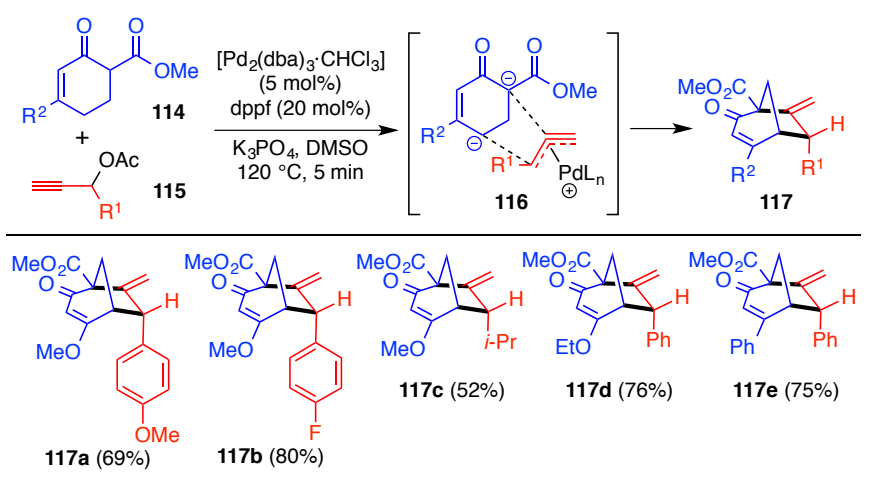

Scheme 25. Diastereoselective cyclization with extended enolates.

More recently, Rawal and co-workers developed a cyclization reaction using oxindole substrates 118, tethered to either a sulfonamide or an amide (Scheme 26). ${ }^{38}$ Depending on the type of amide 
employed, spirooxindole 120 or its regioisomer 121 was obtained, in which a quaternary all-carbon center had been installed. The authors argued that the similarity in the $\mathrm{p} K_{\mathrm{a}}$ values of an oxindole and a sulfonamide or an amide could lead to an equilibrium between an enolate of an oxindole and a nitrogen-centered anion, making the order of addition of the nucleophiles sensitive to the electronwithdrawing nature of the nitrogen substituent. For example, an electron-withdrawing sulfonamide or a phenyl substituent on an amide afforded 120a-c, in which the oxindole enolate had undergone the first nucleophilic addition owing to the reduced nucleophilicity of the nitrogen anion. In contrast, products 121a and 121b were obtained with less powerful electron-withdrawing groups on the nitrogen atom, such as a carbomethoxy or a methyl-substituted amide, wherein the order of addition of nucleophiles had been reversed owing to the more nucleophilic nature of the nitrogen-based anion. These examples illustrate that factors other than acidity, such as relative nucleophilicity and steric effects, could also be at play in determining the regiochemical outcome of the reaction.
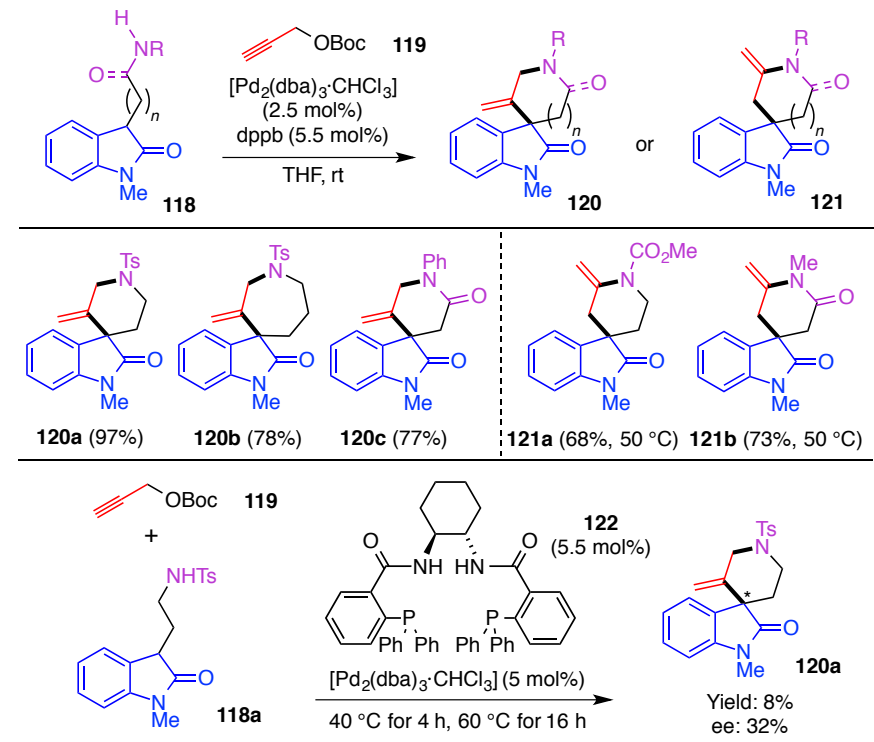

Scheme 26. Cyclization with oxindole enolates.

Crucially, the authors reported the use of chiral Trost phosphine ligand $\mathbf{1 2 2}$ to install the quaternary all-carbon stereogenic center in 120a in an enantioselective manner. Although the yield of 120a was poor and the selectivity only moderate, this is the only report to date, in which the stereogenic center formed through the nucleophile undergoing alkenylation has been installed enantioselectively.

The Rawal group extended this work to the dearomatization of tryptamine derivatives $\mathbf{1 2 3}$ (Scheme $27),{ }^{39}$ in which the nitrogen anion had undergone the initial attack, followed by spirocyclization to install the quaternary carbon center in $\mathbf{1 2 4}$. It can be postulated that the observed regioselectivity in products 124a-d arises from the lower $\mathrm{p} K_{\mathrm{a}}$ value of sulfonamides as compared to that of indoles. The authors were able to perform the allylic alkylation step enantioselectively using BIPHEP derivative $\mathbf{1 2 5}$ as the ligand, thus, installing a quaternary all-carbon center in spirocycle $\mathbf{1 2 4 e}$ with $77 \%$ ee. $^{38}$ 


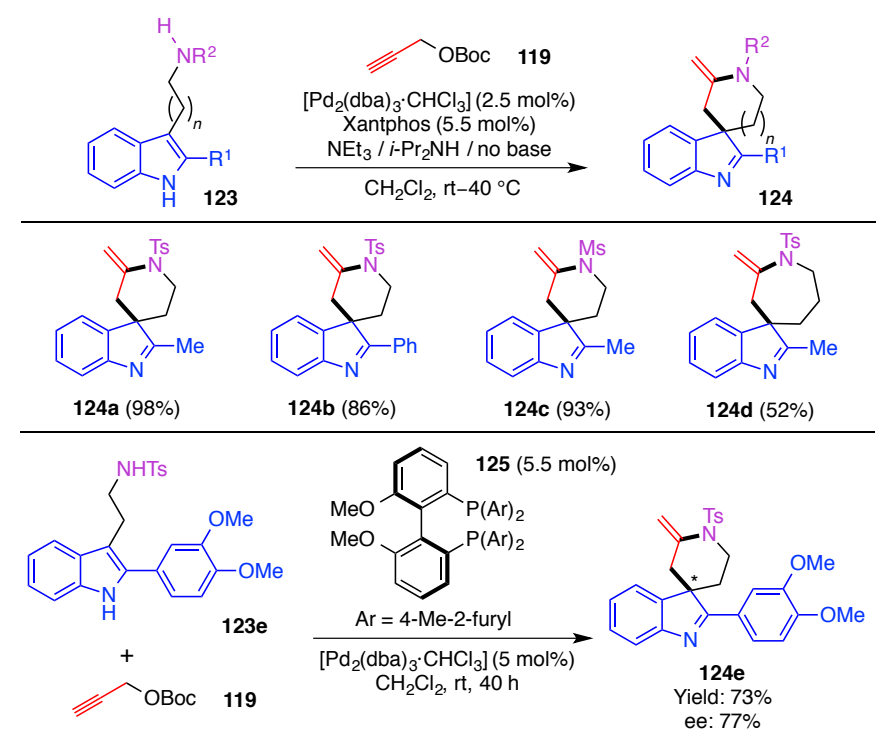

Scheme 27. Dearomatization of tryptamine derivatives.

In an analogous process, You et al. found that the nitrogen nucleophile can be replaced by a malonate in 126 (Scheme 28), ${ }^{40}$ thus giving rise to the installation of new all-carbon quaternary centers in spiroindolenines $\mathbf{1 2 7}$ with the same regioselectivity. A range of ester side-chains and indole substituents were successfully examined $(\mathbf{1 2 7} \mathbf{a}-\mathbf{c})$. Very importantly, with $(R)$-SEGPHOS as the ligand, the quaternary all-carbon stereogenic center in $\mathbf{1 2 7} \mathbf{d}$ was installed enantioselectively with $52 \%$ ee in the dearomatizing allylic alkylation step.

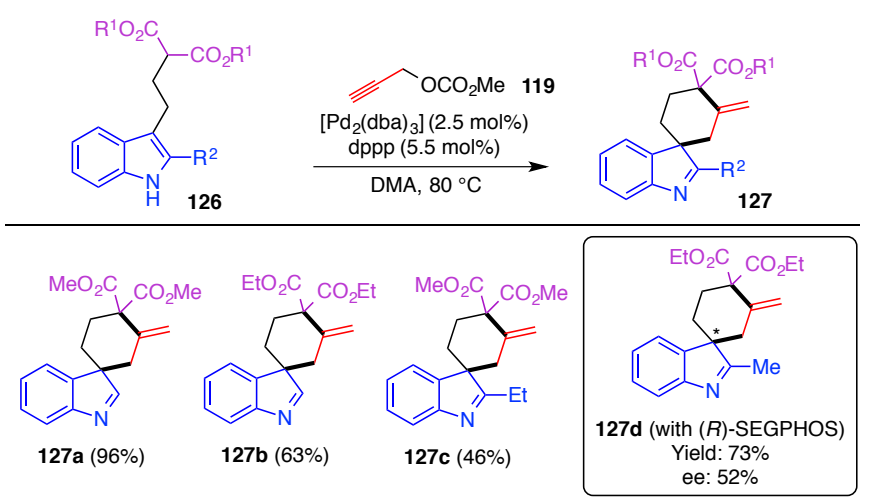

Scheme 28. Dearomatization of indoles in the presence of tethered 1,3-dicarbonyl compounds.

\section{Control of Selectivity: Intermolecular Coupling Reactions of Propargylic Electrophiles with Soft Nucleophiles}

Thus far, the regioselectivity of the reaction of nucleophiles with propargylic electrophiles has utilized tethering strategies. However, if the two nucleophiles were to react with a propargylic electrophile in a purely intermolecular sense, selectivity issues become significantly more challenging (vide supra, A, Scheme 12). More specifically, even with an unsubstituted propargylic electrophile 5 (A, Scheme 29), the order of addition of the two nucleophiles has to be controlled to obtain one regioisomer and not the other (128 versus 129), and the homocoupling process of each of the nucleophiles (chemoselectivity) leading to 130 and 131 must be prevented. Our group sought to develop a selective intermolecular coupling reaction by utilizing propargyl enol carbonate $\mathbf{1 3 2}$ derived from a 1,3-dicarbonyl (B, Scheme 29). We reasoned that, if the $\eta^{3}$ $\pi$-propargylpalladium(II) intermediate remained tightly associated with the enolate in $\mathbf{1 3 3}$ after the decarboxylation step, then addition of the enolate to the central carbon atom of $\eta^{3}$ - 
$\pi$-propargylpalladium(II) intermediate should precede the addition of the external nucleophile owing to the intramolecular nature of the reaction, thereby affording $\mathbf{1 3 4}$ with the control of chemoand regioselectivity.
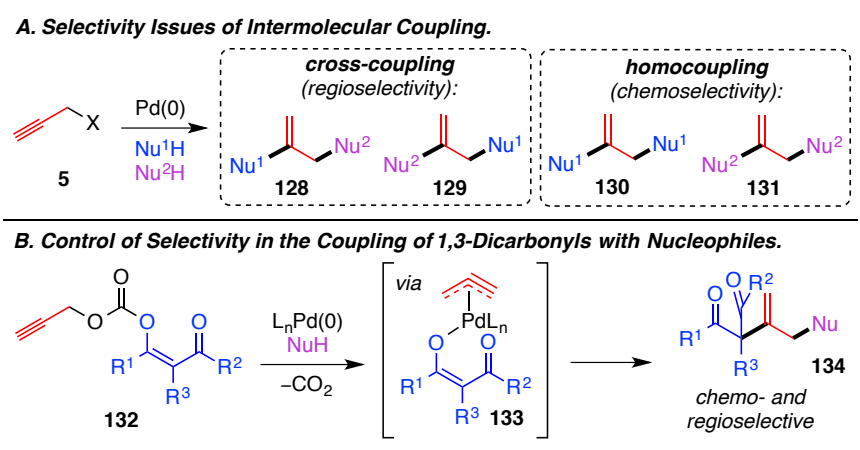

Scheme 29. Control of selectivity in intermolecular coupling reactions.

This strategy proved to be successful in the coupling of propargyl enol carbonates 132 with phenols $\mathbf{7 4}$ to give 135, which contains an all-carbon quaternary center (Scheme 30$).{ }^{41}$ A variety of cyclic and acyclic 1,3-dicarbonyls, as well as phenols decorated with electron-donating, -withdrawing and nucleophilic groups can be readily used, affording products $135 \mathbf{a}-\mathbf{g}$ in high yields with complete chemo- and regioselectivity. Mechanistic studies indicated that the palladium center was indeed tightly associated with the enolate after decarboxylation, resulting in complete control of selectivity.

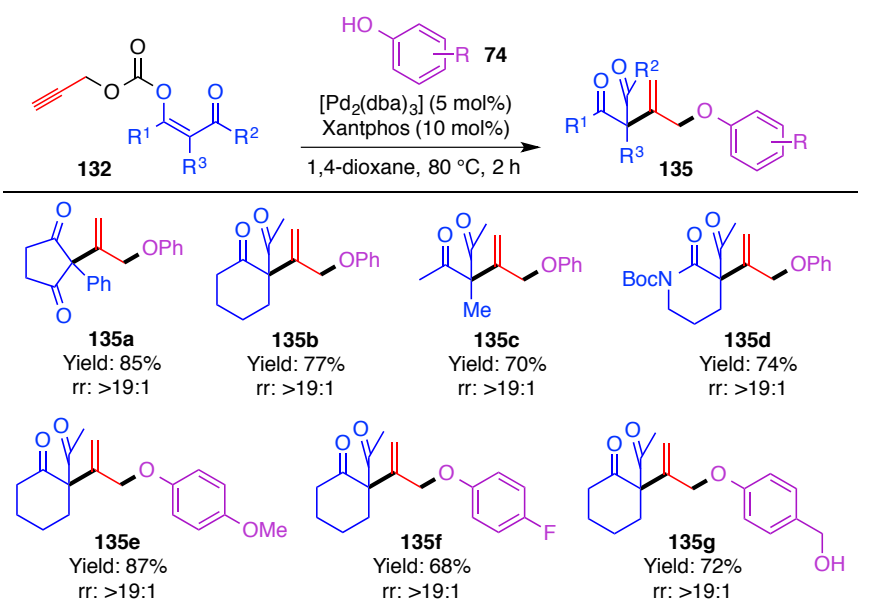

Scheme 30. Intermolecular coupling of 1,3-dicarbonyl compounds with phenols.

Based on this strategy, we subsequently developed the regio- and chemoselective coupling of two different 1,3-dicarbonyl compounds (132 and 136, Scheme 31), one of which underwent an alkenylation and the other, an allylic alkylation reaction in $137 .^{42}$ This process enabled the installation of two new $\mathrm{C}-\mathrm{C}$ bonds and two all-carbon quaternary centers in a single operation with a broad range of carbonyl compounds $(\mathbf{1 3 7 a}-\mathbf{d})$ with complete regioselectivity and good chemoselectivity. Crucially, this reaction is regioswitchable as the regioisomer of each of the products is readily accessible by judiciously using an enol carbonate of the other coupling partner $(137 \mathrm{e}-\mathbf{h})$. 


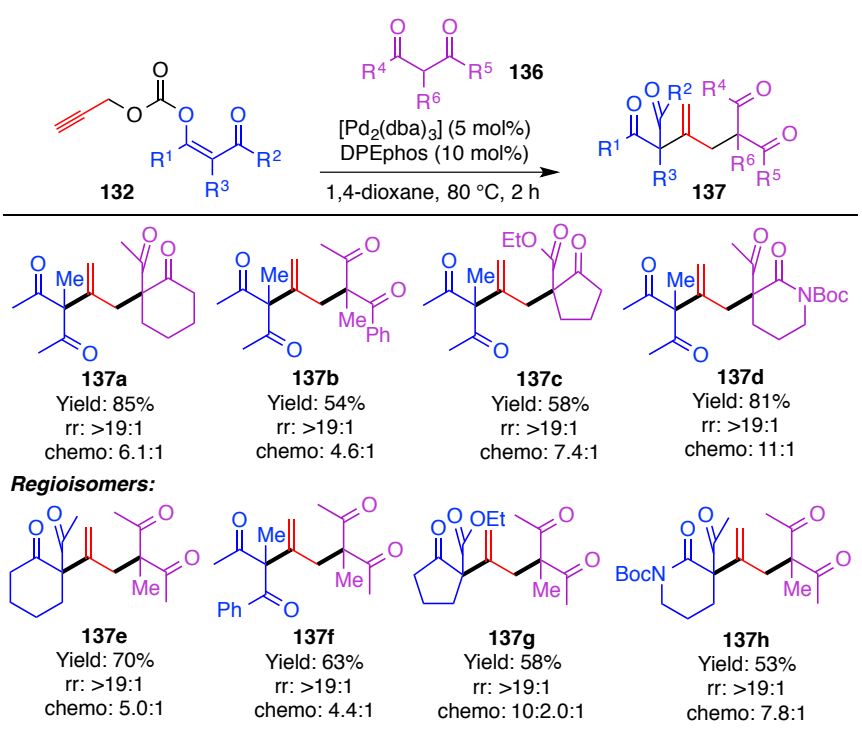

Scheme 31. Intermolecular coupling of 1,3-dicarbonyl compounds.

The success of the above reactions relied on the relatively high acidity of phenols $\mathbf{7 4}$ and 1,3dicarbonyl compounds 136, which protonate the putative palladacyclobutene intermediate (vide supra, Scheme 2). The incorporation of much less acidic nitrogen-based nucleophiles under basefree conditions is more challenging. Pleasingly, we have recently developed reaction conditions that enabled us to successfully incorporate indole and pyrrole nitrogen heterocycles 138 (Scheme 32 ). ${ }^{43}$ The use of propargyl enol carbonate 132 of 1,3-dicarbonyls was again essential for the control of selectivity, paving the way to a library of indole and pyrrole products $139 \mathbf{a}-\mathbf{f}$ with complete regioand chemoselectivity.

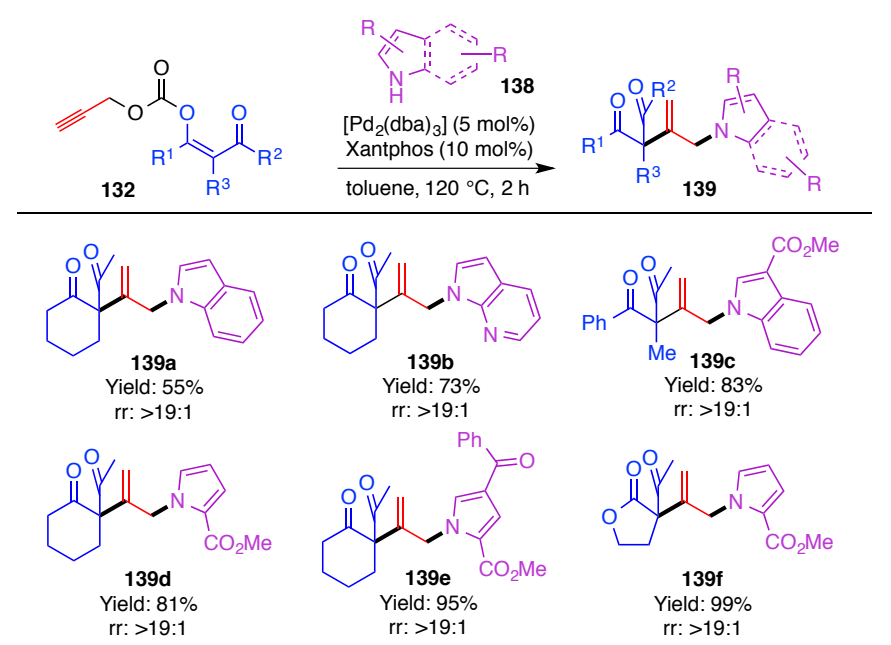

Scheme 32. Intermolecular coupling of 1,3-dicarbonyl compounds with indoles and pyrroles.

\section{Conclusions and Outlook}

The use of propargylic electrophiles in palladium-catalyzed coupling processes offers enormous scope for the generation of quaternary all-carbon centers, particularly in reactions with enolates and dearomatization processes. Most notably, these transformations can enable the coupling of two different nucleophiles, resulting in multiple bond formation and generation of structural complexity in a single operation. However, the broad reactivity profile of propargyl-derived palladium intermediates may have prevented the exploration of these processes to the same extent as those utilizing allylic electrophiles. Indeed, several elegant strategies have been successfully developed and adopted for the control of chemo- and regioselectivity of the reactions, particularly in 
cyclization reactions. More recently, we have discovered how nucleophiles can be coupled intermolecularly. With our understanding of these control elements growing deeper, the enantioselective construction of quaternary all-carbon centers with propargylic electrophiles has recently come to the forefront of this research area. The levels of enantioinduction are still relatively low and very few processes have been explored to date. As such, the growth and expansion of the repertoire of stereoselective methods for the creation of congested chiral centers with propargylic compounds could not be more timely and auspicious.

\section{Acknowledgements}

We gratefully acknowledge the Royal Society (RG150189), Lancaster University and the Royal Society of Chemistry for the generous financial support of the research in our laboratory.

\section{References}

1. (a) Douglas, C. J.; Overman, L. E., Proc. Natl. Acad. Sci. U. S. A. 2004, 101, 5363. (b) Liu, Y. Y.; Han, S. J.; Liu, W. B.; Stoltz, B. M., Acc. Chem. Res. 2015, 48, 740.

2. (a) Lovering, F.; Bikker, J.; Humblet, C., J. Med. Chem. 2009, 52, 6752. (b) Leach, A. R.; Hann, M. M., Curr. Opin. Chem. Biol. 2011, 15, 489.

3. (a) Trost, B. M.; Van Vranken, D. L., Chem. Rev. 1996, 96, 395. (b) Weaver, J. D.; Recio III, A.; Grenning, A. J.; Tunge, J. A., Chem. Rev. 2011, 111, 1846.

4. Tsutsumi, K.; Kawase, T.; Kakiuchi, K.; Ogoshi, S.; Okada, Y.; Kurosawa, H., Bull. Chem. Soc. Jpn. 1999, 72, 2687.

5. (a) Ogoshi, S.; Tsutsumi, K.; Kurosawa, H., J. Organomet. Chem. 1995, 493, C19. (b) Baize, M. W.; Blosser, P. W.; Plantevin, V.; Schimpff, D. G.; Gallucci, J. C.; Wojcicki, A., Organometallics 1996, 15, 164. (c) Tsutsumi, K.; Ogoshi, S.; Nishiguchi, S.; Kurosawa, H., J. Am. Chem. Soc. 1998, $120,1938$.

6. (a) Tsuji, J.; Mandai, T., Angew. Chem. Int. Ed. Engl. 1995, 34, 2589. (b) Ma, S. M., Eur. J. Org. Chem. 2004, 1175.

7. (a) Guo, L.-N.; Duan, X.-H.; Liang, Y.-M., Acc. Chem. Res. 2011, 44, 111. (b) Yoshida, M., Chem. Pharm. Bull. 2012, 60, 285. (c) Yoshida, M., Heterocycles 2013, 87, 1835. (d) Hu, X.-H.; Liu, Z.-T.; Shao, L.; Hu, X.-P., Synthesis 2015, 47, 913.

8. Casey, C. P.; Nash, J. R.; Yi, C. S.; Selmeczy, A. D.; Chung, S.; Powell, D. R.; Hayashi, R. K., J. Am. Chem. Soc. 1998, 120, 722.

9. Cheng, Y.-C.; Chen, Y.-K.; Huang, T.-M.; Yu, C.-I.; Lee, G.-H.; Wang, Y.; Chen, J.-T., Organometallics 1998, 17, 2953.

10. (a) Labrosse, J. R.; Lhoste, P.; Delbecq, F.; Sinou, D., Eur. J. Org. Chem. 2003, 2813. (b)

Daniels, D. S. B.; Jones, A. S.; Thompson, A. L.; Paton, R. S.; Anderson, E. A., Angew. Chem. Int. Ed. 2014, 53, 1915.

11. Yoshida, M.; Gotou, T.; Ihara, M., Tetrahedron Lett. 2004, 45, 5573.

12. Ardolino, M. J.; Morken, J. P., J. Am. Chem. Soc. 2012, 134, 8770.

13. Bienaymé, H., Tetrahedron Lett. 1994, 35, 7387.

14. Bienaymé, H., Tetrahedron Lett. 1994, 35, 7383.

15. Matsuda, I.; Komori, K.; Itoh, K., J. Am. Chem. Soc. 2002, 124, 9072.

16. Behenna, D. C.; Mohr, J. T.; Sherden, N. H.; Marinescu, S. C.; Harned, A. M.; Tani, K.; Seto, M.; Ma, S.; Novak, Z.; Krout, M. R.; McFadden, R. M.; Roizen, J. L.; Enquist, J. A.; White, D. E.; Levine, S. R.; Petrova, K. V.; Iwashita, A.; Virgil, S. C.; Stoltz, B. M., Chem. Eur. J. 2011, 17, 14199.

17. Yoshida, M.; Ohno, S.; Shishido, K., Chem. Eur. J. 2012, 18, 1604.

18. Tsuji, J.; Watanabe, H.; Minami, I.; Shimizu, I., J. Am. Chem. Soc. 1985, 107, 2196.

19. Geng, L.; Lu, X., Tetrahedron Lett. 1990, 31, 111.

20. Geng, L. F.; Lu, X. Y., J. Chem. Soc., Perkin Trans. 1 1992, 17. 
21. Labrosse, J. R.; Lhoste, P.; Sinou, D., J. Org. Chem. 2001, 66, 6634.

22. (a) Labrosse, J. R.; Lhoste, P.; Sinou, D., Org. Lett. 2000, 2, 527. (b) Damez, C.; Labrosse, J. R.; Lhoste, P.; Sinou, D., Tetrahedron Lett. 2003, 44, 557. (c) Dominczak, N.; Damez, C.; Rhers, B.; Labrosse, J.-R.; Lhoste, P.; Kryczka, B.; Sinou, D., Tetrahedron 2005, 61, 2589.

23. Labrosse, J.-R.; Lhoste, P.; Sinou, D., Eur. J. Org. Chem. 2002, 1966.

24. Yoshida, M.; Higuchi, M.; Shishido, K., Org. Lett. 2009, 11, 4752.

25. Duan, X.-H.; Guo, L.-N.; Bi, H.-P.; Liu, X.-Y.; Liang, Y.-M., Org. Lett. 2006, 8, 5777.

26. Guo, L.-N.; Duan, X.-H.; Bi, H.-P.; Liu, X.-Y.; Liang, Y.-M., J. Org. Chem. 2007, 72, 1538.

27. Guo, L.-N.; Duan, X.-H.; Liu, X.-Y.; Hu, J.; Bi, H.-P.; Liang, Y.-M., Org. Lett. 2007, 9, 5425.

28. Bi, H.-P.; Liu, X.-Y.; Gou, F.-R.; Guo, L.-N.; Duan, X.-H.; Liang, Y.-M., Org. Lett. 2007, 9 , 3527.

29. Shi, Y.; Huang, J.; Yang, Y.-F.; Wu, L.-Y.; Niu, Y.-N.; Huo, P.-F.; Liu, X.-Y.; Liang, Y.-M., Adv. Synth. Catal. 2009, 351, 141.

30. Bi, H.-P.; Guo, L.-N.; Gou, F.-R.; Duan, X.-H.; Liu, X.-Y.; Liang, Y.-M., J. Org. Chem. 2008, $73,4713$.

31. Ren, Z.-H.; Guan, Z.-H.; Liang, Y.-M., J. Org. Chem. 2009, 74, 3145.

32. (a) Yoshida, M.; Morishita, Y.; Fujita, M.; Ihara, M., Tetrahedron Lett. 2004, 45, 1861. (b)

Yoshida, M.; Morishita, Y.; Fujita, M.; Ihara, M., Tetrahedron 2005, 61, 4381.

33. Nemoto, T.; Zhao, Z. D.; Yokosaka, T.; Suzuki, Y.; Wu, R.; Hamada, Y., Angew. Chem. Int. Ed. 2013, 52, 2217.

34. Iwata, A.; Inuki, S.; Oishi, S.; Fujii, N.; Ohno, H., Chem. Commun. 2014, 50, 298.

35. Yoshida, M.; Higuchi, M.; Shishido, K., Tetrahedron Lett. 2008, 49, 1678.

36. Yoshida, M.; Higuchi, M.; Shishido, K., Tetrahedron 2010, 66, 2675.

37. Yoshida, M.; Sugimura, C.; Shishido, K., Org. Lett. 2011, 13, 3482.

38. Nibbs, A. E.; Montgomery, T. D.; Zhu, Y.; Rawal, V. H., J. Org. Chem. 2015, 80, 4928.

39. Montgomery, T. D.; Nibbs, A. E.; Zhu, Y.; Rawal, V. H., Org. Lett. 2014, 16, 3480.

40. Gao, R.-D.; Liu, C.; Dai, L.-X.; Zhang, W.; You, S.-L., Org. Lett. 2014, 16, 3919.

41. Schröder, S. P.; Taylor, N. J.; Jackson, P.; Franckevičius, V., Org. Lett. 2013, 15, 3778.

42. Kenny, M.; Christensen, J.; Coles, S. J.; Franckevičius, V., Org. Lett. 2015, 17, 3926.

43. Kenny, M.; Kitson, D. J.; Franckevičius, V., J. Org. Chem. 2016, 81, 5162. 